\title{
Exploring the Impact of Global Studies Experiences on Undergraduate Student Development: Some Curricular Considerations
}

\section{Christopher J . Stephens}

St. Louis Community College

\section{Z Hamison Morford \\ Traci M. Cihon \\ Elissa Hamilton Forand \\ Lucero Neri-Hemández \\ University of North Texas}

\begin{abstract}
:
In this manuscript, the authors detail the initial evaluations of the effects of participation in two iterations of an interdisciplinary learning community with a short-term study abroad opportunity on undergraduate student learning and behavior. The results suggest that the CHE (Cultural, Historical, and Environmental) log tool may be useful in capturing information about students' interactions with their native and foreign environments and how their experiences further affect their later interactions with their native environment. These findings are discussed in terms of methodological revisions made to the procedures and experimental methods to strengthen the reliability and validity of the conclusions and the implications for integrating teaching and scholarship in mutually beneficial ways.
\end{abstract}

With an increased emphasis on outcomes-based curriculum design and assessment (Kuh \& Ikenberry, 2009), higher education has been under fire to produce standards-based education and assessment processes. Under these conditions, study abroad programs are readily criticized due to the substantial financial cost for students who study abroad (Sutton, Miller, \& Rubin, 2007). Shortterm study abroad opportunities have been developed as an economic alternative to full length study abroad programs. However, there is some debate regarding the effectiveness of short-term experiences, particularly as to whether or not short-term experiences can produce the same outcomes as long-term experiences (Allen, 2010). Nonetheless, a general dearth of evidence exists regarding both short-term experiences and study abroad in general (Bolen, 2007). Steinberg (2002) and Bolen (2007) have issued pleas to faculty and researchers to develop instruments that holistically measure student learning outcomes. Many faculty members, while researchers in their own 
disciplines, do not have research expertise as it pertains to the scholarship of teaching and learning. Often those engaged in international work and global studies rely on surveys as measures of achievement of student learning outcomes (Braskamp, Braskamp, \& Merrill, 2009; Chieffo \& Griffiths, 2004; Ingraham \& Peterson, 2004; Kehl \& Morris, 2007/2008; Sutton \& Rubin, 2004; Tajes \& Ortiz, 2010) while others develop specific student learning outcomes and measure the participating students' acquisition of the target domains (Williams, 2009).

In one recent study, Braskamp et al. (2009) offered an approach to measuring the impact of study abroad experiences from the theoretical perspectives of human development and intercultural communication. Braskamp et al. used a pretest-posttest design to assess the change in students' selfreports (via the Global Perspective Inventory; GPI ${ }^{1}$ ) of global learning and development in cognitive, intrapersonal and interpersonal domains before and after a semester-long study abroad experience. Participating students represented a sample from ten semester-long programs occurring at five universities. Their results suggested that students reported changes in each of the domains measured by the GPI after taking part in a semester long study abroad experience. However, the study is limited in the sense that it relied solely on students' perceptions of change in the measured domains and did not allow for an analysis of the students' development throughout the study abroad program, assessing differences at only two points in time (pre and post study abroad).

On the other hand, Williams (2009) proposed a multidimensional, qualitative approach to assessing student learning outcomes through study abroad to attempt to gain a deeper understanding of student learning outcomes and development as a function of participating in study abroad experiences. Williams developed the Reflective Model of Intercultural Competency, based on specific learning outcomes for her course and covering three dimensions: cognitive, affective and behavioral. She evaluated whether or not the participating students met the objectives with an end of semester photo contest which required students to visually depict a subject inspired by the outcome, a reflection based on it, and responses to a pre and post study abroad interview. Williams reported positive results that demonstrated the value of study abroad on student development. Yet, the scope of the work was limited in that the data reported seemed to reflect the performances of only select students or those representing "best outcome" repertoires rather than examples that represented the range of possible student performances.

Braskamp et al. (2009) and Williams (2009) offered much needed empirical analyses of the effects of study abroad experiences on student learning and behavior. Their data suggested student learning outcomes and development in the stated areas of interest over the course of the study abroad program. However, without continuous measurement throughout the study abroad experience, researchers and faculty members cannot clearly identify the relation between study abroad and the changes in student behavior. For example, in the aforementioned studies, it is possible that students might have changed their responses to the GPI or structured interviews as a function of other coursework, experiences outside of the study abroad program, or simply by way of maturation.

\footnotetext{
1 The GPI was created by Braskamp, Braskamp, and Engberg (2014) to assess points of development along a continuum
} of how individuals "think, feel, and relate to others" (p. 4). 
In an attempt to better understand the developmental process that occurs within the study abroad experience, Cihon et al. (2012) used an assessment approach that asked students to complete structured, reflective journal entries called CHE (Cultural, Historical, and Environmental) logs which were modeled from Goldiamond's (1974/2002) exploratory logs and Tajes and Ortiz's (2010) SLEPT framework. Eleven students, who were enrolled in a Global Education course (GLE 101) and who were members of the Italian Studies Learning Community (ISLC), were asked to complete CHE logs before, during and after a short-term study abroad program to Italy offered through a community college; to categorize these observations as cultural, historical, or environmental (no category was given more or less importance/weight than another); and to provide an experience evaluation of positive, negative, or neutral. Cihon et al. used CHE log entries to evaluate the impact of short-term experiences on student learning outcomes and development of intercultural competency. Only seven students submitted CHE logs prior to the study abroad trip; nine students submitted logs from during the study abroad trip; and only one student submitted a log following the study abroad trip. The results suggested that participants reported more positive experience evaluations during the trip than prior to the trip. Nevertheless, due to the limited number of post study abroad entries, the long-term change for participants could not be evaluated. In further data analysis ${ }^{2}$, Cihon and colleagues found that the majority of participating students also expanded their observations during the study abroad experience, categorizing their entries across more of the available categorizations. Nonetheless, the unavailability of post-study abroad logs limits the conclusions Cihon et al. (2012) could make regarding the utility of the tool to quantify the ongoing impact of study abroad experiences on student learning and behavior.

The current study focused on extending the efforts made thus far to quantify the effects of participation in short-term study abroad experiences embedded in an interdisciplinary learning community $^{3}$ on student learning and behavior by replicating and extending Cihon et al. (2012). First, the procedures were employed with two separate study abroad programs to increase the number of participants. Second, experimenters placed grade contingencies on the number of required logs in an effort to increase the number of responses post-travel. Third, the current authors included an analysis of $\mathrm{CHE}$ categories students selected as well as an analysis of the experience evaluations before, during, and after the short-term study abroad programs.

The specific research questions addressed were 1) Do grade contingencies associated with each set of logs promote student completion of CHE logs across all experimental conditions? 2) Do $\mathrm{CHE} \log$ entries associated with the $\mathrm{CHE}$ categories vary as a function of experimental conditions and if so, what are the differences between log entries from pre-trip to during trip, during trip to post-trip, and pre-trip to post-trip? and 3) How do student experience evaluations compare from pre-trip to during trip, during trip to post-trip, and pre-trip to post-trip?

\footnotetext{
2 Unpublished data; available by contacting the third author.

${ }^{3}$ Learning communities have become a mainstay on college campuses due to their documented impact on student learning outcomes (Hegler, 2004; Kuh, 2008; Lardner \& Malnarich, 2008/2009). Further, learning communities present an effective framework for embedding global studies experiences in an ideal environment in which to study their effects (Cihon \& Stephens, 2011; Cihon, Stephens, \& Dean, 2012; Stephens \& Florini, 2010).
} 


\section{Method}

\section{Partic ipants}

Participants were recruited from individuals who were members of the ISLC and who were enrolled in one of two sections of GLE 101 at a midwestern community college. Thirty-five students enrolled in the first section of the course: eleven who were taking the course for a grade, and twenty-four who were auditing the course. From the first course section, twelve students consented to participate in the study. Of those twelve students, eight graded students and one auditing student submitted CHE logs.

Ten students enrolled in the second section of the course, all of whom were taking the course for a grade. All of the students enrolled in the second section of the course consented to participate in the study and submitted CHE logs.

In order for students' data to qualify for inclusion in data analysis, each student had to complete a CHE log entry at least once in all of the following experimental conditions: before, during, and after the study abroad experience. Five students from the first course section (one male and four females) met this criterion and their data were analyzed. Five students from the second course section also (one male and four females) met this criterion and their data were analyzed.

\section{Setting and Materials}

The experimenters conducted the study at the community college and during the study abroad experiences in Italy. The only materials needed were the CHE logs, which were provided to all students by the first and second authors as a bound notebook that included enough copies to exceed the requirements of the course.

The CHE logs included the following columns (column titles in parentheses): date and time of the entry, location in which the entry occurred, CHE category selection represented by the entry (see below for CHE category definitions), expectation ("What I Expected"), observation ("What I Saw"), reflection on the observation ("Reflection"), and experience evaluation ("How I Felt"; positive, negative, and/or neutral) regarding the log entry (e.g., Cihon et al., 2012).

The CHE categories were Cultural, Historical, and Environmental ('che' also happens to translate to 'what' in Italian). The Cultural category could include observations that referred to aesthetic, linguistic, lifestyle, and/or social stimuli. The Cultural category was further defined as the category in which students should record observations of cultural practices. See Figure 1, top panel, for examples of statements students labeled as Cultural. The Historical category was provided for students to specify observations of how a historical event or artifact may have had (or continues to have) an impact on current practices. See Figure 1, middle panel for examples of statements students labeled as Historical. The Environmental category was designed to capture observations regarding how artificial (e.g., university practices) and/or natural (e.g., landscape or terrain) contexts/locations impacted the observation. See Figure 1, bottom panel for examples of statements students labeled as Environmental. 
Figure 1. Sample CHE log entries by category. Top panel - Cultural entries; middle panel - Historical entries; bottom panel - Environmental entries.

\begin{tabular}{|l|l|l|l|}
\hline Year & Location & What I saw & Reflection \\
\hline 2012 & $\begin{array}{l}\text { USA - Italian } \\
\text { Cafe }\end{array}$ & $\begin{array}{l}\text { When we made a stop at the café, the food } \\
\text { was unbelievable, what blew my mind was } \\
\text { that was their version of fast-food. }\end{array}$ & $\begin{array}{l}\text { If that was considered fast-food, then I cannot } \\
\text { wait to taste their restaurant quality food. }\end{array}$ \\
\hline $\begin{array}{l}\text { Italy - Isola di } \\
\text { San Ginlio }\end{array}$ & $\begin{array}{l}\text { On the little island on Lago d'orta, saw a } \\
\text { very impressive Basilica were excellent. } \\
\text { Fresco painting. Monls on the island placed } \\
\text { mainly identical signs on the streets. }\end{array}$ & $\begin{array}{l}\text { The signs mostly talk about silence and listening } \\
\text { "La del silenxio". "Ascolta il silenzio". "Nel } \\
\text { silencio accetti e comprendi". Etc. These are great } \\
\text { advice for people who are not used to listen and } \\
\text { love to talk non-stop. We americans tend to } \\
\text { preach to others too much without really-trying to } \\
\text { understand the issues. Maybe we can send some } \\
\text { of the politicians here. }\end{array}$ \\
\hline
\end{tabular}

\begin{tabular}{|l|l|l|l|}
\hline Year & Location & What I saw & Reflection \\
\hline 2012 & Italy - Sagesta & $\begin{array}{l}\text { I saw a really awesome, very huge temple. It } \\
\text { was the first temple I've actually seen first } \\
\text { hand. Also, I saw an awesome but huge } \\
\text { Greek theatre. }\end{array}$ & $\begin{array}{l}\text { I felt wowed, almost speechless. The theatre was } \\
\text { the best part about today. It was overall an } \\
\text { awesome experience. }\end{array}$ \\
\hline 2013 & $\begin{array}{l}\text { USA - Egyptian } \\
\text { Museum }\end{array}$ & $\begin{array}{l}\text { Our tour guide was explaining that some } \\
\text { status depict couples sitting next to each } \\
\text { other and she pointed out that 2 women were } \\
\text { sitting as a couple. }\end{array}$ & $\begin{array}{l}\text { This to me really showed how open the Egyptian } \\
\text { culture was about sexuality. It translates to me, } \\
\text { that the culture has still remained open about } \\
\text { sexuality today. But not only in their culture, but } \\
\text { others as well. }\end{array}$ \\
\hline
\end{tabular}

\begin{tabular}{|l|l|l|l|}
\hline Year & Location & What I saw & Reflection \\
\hline 2012 & Italy - Mt. Etna & $\begin{array}{l}\text { I saw lots of vegetation along the trail. As I } \\
\text { walked up the trail toward Mt. Etna. The } \\
\text { trees had pinelike needles as well as volcanic } \\
\text { rocks. }\end{array}$ & $\begin{array}{l}\text { I felt enthralled due to the vegetation that I was } \\
\text { surrounded by. The vegetation looked } \\
\text { extraterrestrial + the trees, the ground looked like } \\
\text { the Earth's terrain. Yet the terrain of Mt. Etna was } \\
\text { very distinct. }\end{array}$ \\
\hline USA - St. Louis & $\begin{array}{l}\text { I was driving on the highway and it } \\
\text { reminded me of how different St. Louis is } \\
\text { constructed versus Chicago }\end{array}$ & $\begin{array}{l}\text { I had to go to the Four Seasons that is downtown, } \\
\text { and I became annoyed with the layout of the } \\
\text { streets. I accidently went over some bridge and } \\
\text { ended up in the Illinois somehow. I have yet to } \\
\text { become accustomed to driving in St. Louis. In my } \\
\text { opinion, driving in Chicago is easier and, a lot of } \\
\text { important areas can be reached sans highways. }\end{array}$ \\
\hline
\end{tabular}

\section{General Course Description}

To maximize the potential impact of short-term study abroad, the GLE 101 course prepared students for the experience by facilitating student development of areas of inquiry specific to the study abroad experience, introducing students to cultural, historical, and environmental aspects of Italy applicable to the current year's ISLC focus, and facilitating lectures/presentations on various 
topics of importance to the region being visited. During the preparation for travel and associated learning experiences, emphasis was on the enhancement of intercultural competency (e.g., Deardorf, 2006). In Italy, the course provided the structure for the immersion experience during spring break. Upon return, the students engaged in continued research and in a culminating experience in the form of a symposium where they presented their learning outcomes in a discipline-appropriate format.

GLE 101, the ISLC, and its study abroad program involve an intergenerational community of students, community members, and faculty who engage in a collective, cross-disciplinary study of a region of Italy that includes travel and cultural immersion. A combination of class work, research, and mentor relationships facilitate the exchange of current knowledge and interests and newly cultivated areas of inquiry and expertise. New ideas develop within the rich humanism of Italian culture in the context of its historical artifacts and its contemporary environment.

The members of the ISLC contribute to its success, often bringing specialized expertise and modeling lifelong learning to the community. Faculty serve as guest lecturers and mentors in the program's classroom component. They also incorporate their participation into their professional development plans by developing specific learning objectives that are later incorporated into courses in their respective disciplines and by formulating strategies that enhance instruction. Faculty members typically represent disciplines such as behavior analysis, business, communications, dietetics, education, fine arts, history, Italian language, mathematics, music, psychology, and theatre.

All participants in the ISLC enroll in GLE 101, which focuses on Italian culture including language for travelers), history, and environment. There is also an optional intensive language course (Elementary Italian I [ITL 103]), in which teaching of the Italian language occurs. ITL 103 is designed to supplement the experience of students seeking a more thorough immersion and research experience by developing basic language proficiency.

The overall curriculum, study abroad experience, and Italian course have evolved based on ongoing participant assessment, program review, and research on its outcomes and effectiveness. Graduates who have participated in this program have successfully transferred to pursue bachelor and master's coursework and have received scholarship support.

After completion of GLE 101, students are expected to be able to:

1. Describe an identified area of inquiry as explored prior to, during, and after the study abroad experience.

2. Evaluate Italian and American culture through its cultural (linguistic, aesthetic, lifestyle, social), historical, and environmental manifestations.

3. Comment, via self-reflection and journaling, on their expectations of events that occurred before, during, and after the study abroad experience through cultural (linguistic, aesthetic, lifestyle, social), historical, and environmental categories per CHE log entries.

4. Compare and contrast their expectations with what actually occurred before, during, and after the study abroad experience. 
5. Provide an evaluative statement about how they felt regarding their expectations and what actually occurred before, during, and after the study abroad experience.

In both course sections, students' overall course grades were determined based on attendance and participation, experience assessments (section 2 only), the completion of a final research project, pre-trip study abroad CHE logs, during study abroad CHE logs, and post-trip study abroad CHE logs. Point contingencies varied slightly in each course section and are summarized in Table 1.

Table 1. Percentage of final grade for course components for each course section

\begin{tabular}{lll}
\hline Activity & \multicolumn{1}{c}{ Percentage of Grade } \\
\hline & \multicolumn{1}{c}{ Section 1 } & Section 2 \\
Attendance \& Participation & $25 \%$ & $30 \%$ \\
Final Research Project & $15 \%$ & $20 \%$ \\
Experience Assessments & $\mathrm{n} / \mathrm{a}$ & $5 \%$ \\
Pre-trip study abroad CHE logs & $20 \%(14 \operatorname{logs})$ & $15 \%(12 \operatorname{logs})$ \\
During study abroad CHE logs & $20 \%(18$ logs $)$ & $15 \%(18 \operatorname{logs})$ \\
Post-trip study abroad CHE logs & $20 \%(10$ logs $)$ & $15 \%(8 \operatorname{logs})$ \\
\hline
\end{tabular}

Both course sections met once per week on Fridays for $50 \mathrm{~min}$ in the afternoon. Class met for seven weeks prior to the study abroad experience, did not meet during the study abroad experience, and met for five weeks following the study abroad experience.

\section{Experimental Conditions}

Pre-trip. In the first class session ${ }^{4}$, the course instructor (first author) introduced the syllabus, course requirements, and CHE categories (with examples and non examples of log entries [e.g., Cihon et al., 2012]). In subsequent class meetings prior to the study abroad experience, multidisciplinary faculty members of the ISLC presented on cultural, historical, and environmental topics specific to the region of Italy on which the study abroad experience focused. For example, a history professor presented on the major historical events in Sicily while a dietetics professor presented on the cuisine of Sicily. The instructor asked students to turn in two logs per week (Section 1 = fourteen entries; Section 2 = twelve entries).

During the trip. The study abroad experience spanned a length of nine days. During this time students travelled to several destinations in various regions of Italy. Students travelled to each location by bus, and spent no more than a day and a half at any given location. Destinations included popular cities, landmarks, and tourist attractions, as well as a variety of less frequently travelled locations.

During the trip, students had opportunities to interact with and learn from the professors, graduate students, and community members also on the trip. In addition, students had a multitude of chances to interact with native Italians. Students would frequently divide themselves up into smaller groups and travel together but apart from the larger ISLC. The trip was equally balanced between guided tours, structured activities, and free time. The instructor asked the students to turn in two logs per day (18 entries).

\footnotetext{
${ }^{4}$ Course syllabi and study abroad schedules/activities are available by contacting the first author.
} 
Post-trip. In the weeks remaining in the semester, the instructor met with the students five times. In these classes, the course instructor supported the students in finalizing their research projects, developing their symposium presentations, and enhancing their presentation skills. In the last class meeting, the students participated in a campus-wide symposium during which each student gave a 10-minute presentation regarding their research. The instructor asked students to turn in two logs per week during this time (Section 1 = ten entries; Section $2=$ eight entries).

\section{Response Measurement}

Researchers separated each participant's log entries proportionately by the CHE categories. For example, if a participant categorized an entry as both linguistic and historical, the researcher would assign a value of 0.5 toward each respective column - cultural and historical. Researchers then calculated the sum of the proportion of entries in each category for pre-trip, during trip, and posttrip log entries. Experience evaluations were calculated in a similar manner; however, proportion calculations were not necessary. It was possible for one evaluation to be recorded for each $\mathrm{CHE} \log$ entry, and this evaluation was scored as positive $(+)$, negative $(-)$, or neutral $(\mathrm{N})$. Many log entries did not have an associated experience evaluation, thus researchers created a "not rated" category post hoc to reflect those entries. Researchers then calculated the percentage of each experience evaluation out of the total number of group pre-trip, during trip, and post-trip log entries.

\section{Results}

The data in Figure 2 show the distribution of entries across students in each of the four CHE log categories. Across all three experimental conditions students logged the most in the Cultural category (61.6\% of pre-trip, $37.2 \%$ of trip, and $49.5 \%$ of post-trip logs), though there was a $24.3 \%$ drop in the percentage of entries logged in this category during the trip. There was a corresponding increase in percentage of entries logged in the Historical $(+11.1 \%)$ and Environmental categories $(+10.6 \%)$ during the trip. Following the trip, students logged less in the Historical $(-12.4 \%)$ and Environmental categories $(-2.9 \%)$, and more in the Cultural category $(+12.3 \%)$. Students logged a greater proportion of entries in the Environmental category during the trip relative to pre-trip and post-trip logs. However, students still logged a greater proportion of entries in this category posttrip than pre-trip. Lastly, there was an increase in the percentage of CHE log entries labeled as "Other" or "N/A" across all conditions (from pre-trip to during $+2.7 \%$ and from during to posttrip $+2.9 \%$ ). 


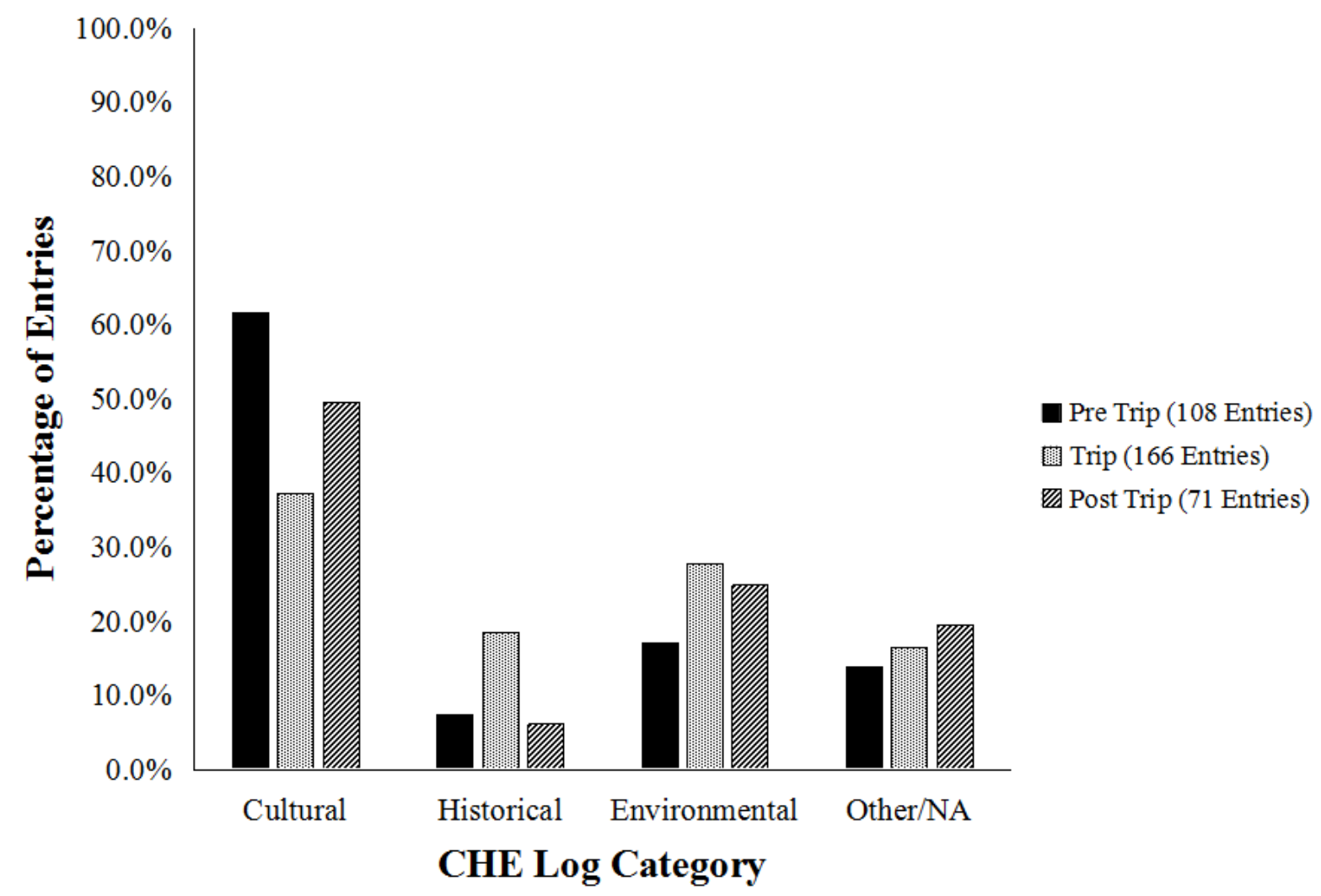

Figure 2. The percentage of categories before, during, and after the study abroad trips the participants categorized as Cultural, Historical, Environmental, and Other/NA. These data are aggregated across the 2012 and 2013 study abroad trips.

The results of the experience evaluations are in Figure 3, which depicts the aggregated ratings of participants' CHE log entries before, during, and after the trip. The results show the highest percentage of unrated entries prior to the trip and the lowest percentage of unrated entries after the trip. Participants indicated the highest percentage of positive evaluations during the trip and the lowest percentage of positive evaluations before the trip. After the trip, as compared to before the trip, participants evaluated a higher percentage of entries as positive and evaluated a higher percentage of entries as negative. Across all three conditions participants indicated higher positive evaluations than negative or neutral evaluations. Participants rated a higher percentage of categories as neutral than they rated as negative both before and during the trips. However, they rated a higher percentage of categories as negative after the trip. 


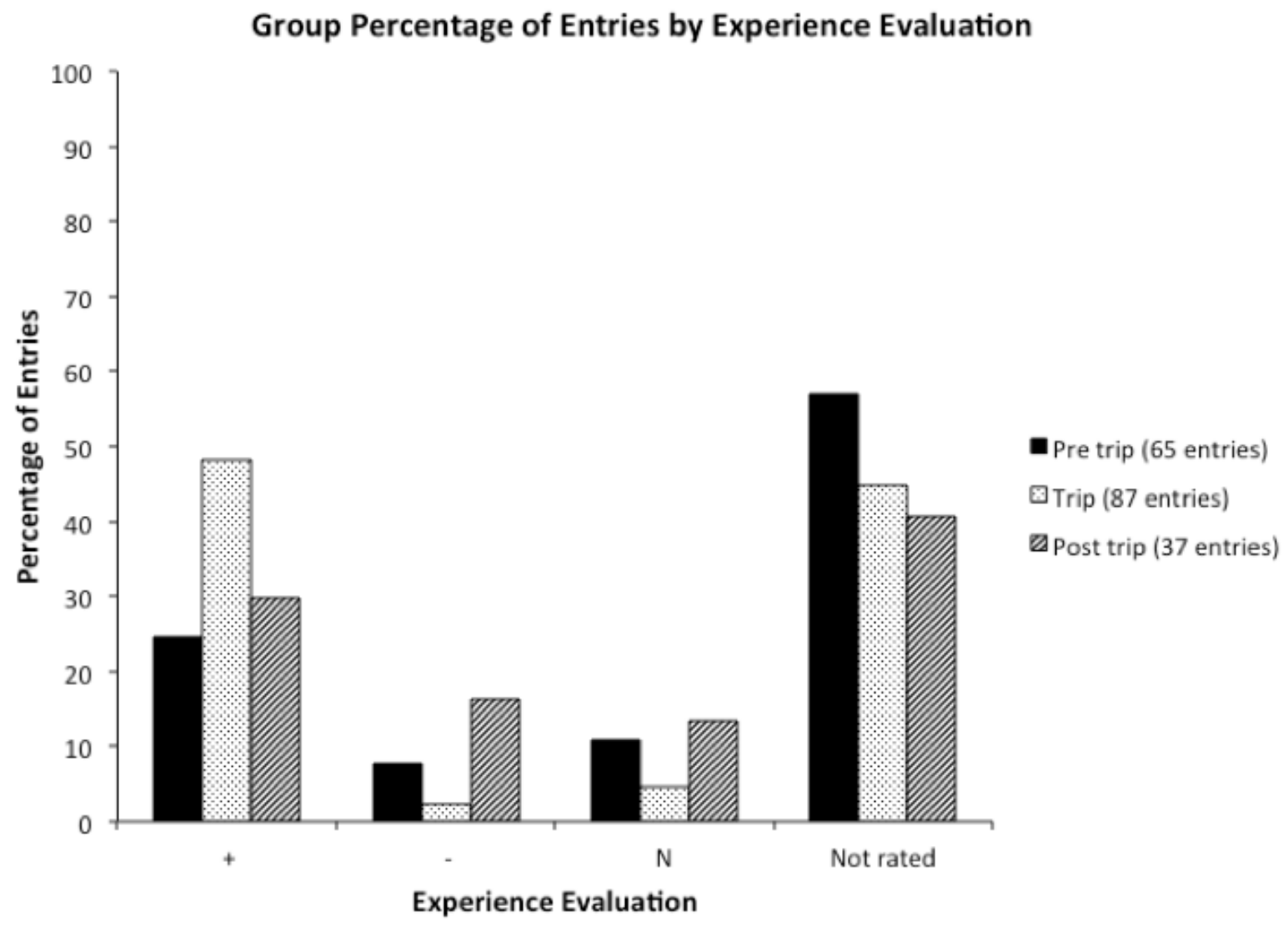

Figure 3. The percentage of categories before, during, and after the study abroad trips the participants categorized as positive, negative, neutral, or not rated. These data are aggregated across the 2012 and 2013 study abroad trips.

\section{Disc ussion}

The results show an orderly pattern in the observations students made in their native and the study abroad environments. Specifically, the data show an increase in the Historical and Environmental categories during the trip, and a subsequent decrease upon returning home. The data also show an increase in positive categorizations during the trip, and a subsequent decrease upon returning home. These data suggest that the CHE log may be a useful tool to help to capture the observations of students who participate in short-term study abroad experiences, especially if participating students continue to use the CHE log following the study abroad program.

One limitation of Cihon et al. (2012) was the lack of post-trip logs. In the current study, experimenters arranged a grade contingency to promote post-trip logging. The grade contingency was effective for ten participants (across the two courses) who submitted frequent post-trip logs; however, twelve consenting participants (across the two courses) did not log post-trip. This attrition, while improved over Cihon et al., still raises pedagogical questions. There are multiple variables of which this attrition could be a function. The nature of this study abroad program is that not all participants enroll for credit; some may enroll under audit status. It is possible that a grade contingency does not incentivize students or that the points were too delayed in delivery (e.g., 
Michael, 1991). The value of the short-term study abroad experience may be diminished if the attrition rate remains high immediately following travel. Although, the problems with attrition seen here and also in Cihon et al. may not be linked to only short term study abroad. It is possible that post-trip attrition is problematic across all study abroad program lengths (e.g., five-week, semester long) but was uncovered here as a function of our course design that required several CHE log entries following the trip. As previously noted, the design that we employ measures students' responding continuously and over longer durations than other research in study abroad that is restricted to pre-post trip designs that would prevent post-trip attrition from being discovered. Perhaps the noted increase in post-trip participation (as compared to Cihon et al., 2012) indicates a need to balance the advantages and disadvantages to short term study abroad in this context. Further inquiry is needed to determine how the structure of a semester long course with a shortterm study abroad component can be designed to encourage continued course and learning community participation and engagement following the study abroad experience. Faculty leading study abroad programs would not set out with the intention that students would study abroad and then not think about it again or not bring something back to their home institution. More thoughtful and integrative curricular design, including post-trip reentry considerations that maximize access to the contingencies that maintain the behavior of students and faculty who would be deemed as "global citizens," needs to be investigated.

The point contingencies for logs were arranged in such a way that students could not receive a passing grade in the course if they did not fill out CHE logs for more than one condition (pre-, during, or post-trip). Perhaps future research should allocate a higher percentage of points to the post-trip log requirements in order to drive additional responding in that condition where attrition seems most probable to occur. However, driving responding on reflective journal entries with point contingencies then presents its own challenges in interpreting the resulting entries. It is possible that with point contingencies driving responding, the students' CHE log entries may be "forced" and not truly indicative of their "natural" observations and experiences before, during and after study abroad experiences. As such, the data from the current study and those from additional studies in which point contingencies are allocated to students' completion of assessments should be interpreted with caution as data may not be reflective of student development during the course of a study abroad program. Rather, the findings may be an artifact of completing course assignments for a grade. Nonetheless, it would be difficult to get students responding during a course if grade contingencies are not in effect.

Even though point contingencies for $\mathrm{CHE} \log$ completion were incorporated into this study, the resulting data are still only representative of a small population of students $(\mathrm{N}=10)$. Therefore, the generality (e.g., Baer, Wolf, \& Risley, 1968) of the results is limited. Moreover, the current study did not incorporate the use of an experimental and a control group. As a result, it is difficult to state with any certainty that a group of students who used the CHE log but did not take the GLE 101 course, participate in the ISLC, and take part in a short-term study abroad program to Italy might not produce similar outcomes. Additional research that uses this experimental arrangement is warranted.

The interdependent relationship between teaching and research often presents challenges to educators and researchers. At times, the two seem to have very distinct needs that conflict with each 
other when the needs of the student compromise the integrity of the research or the research design restricts the flexibility of the instructor. Yet, one without the other may limit teaching effectiveness if faculty employ non-empirically based instructional strategies and if researchers ask questions that may not be of interest to faculty. This research represents the authors' attitudes and behaviors toward teaching, course design, and assessment that are influenced by the research and, in turn, influence the ensuing program of research. The CHE log, for example, could be used as a teaching tool which might impact students' motivation to continue producing the reflective journal entries following a study abroad experience. It could assist study abroad faculty advisors to obtain a baseline level of what types of observations (Cultural, Historical, \& Environmental) students are making prior to going abroad. The course instructor could then arrange more specific instruction and course-based activities to facilitate student observations in particular areas. For example, in a study abroad program that is focused on sustainable tourism, instructors could prime students to make more observations in the Environmental category; in a study abroad program focused on regional cuisine instructors could prime students to make more observations in the Cultural category. Similar to the way Goldiamond (1974/2002) used exploratory logs to help clinical patients to identify patterns in their environment that contributed to them not meeting their goals, the CHE logs could be used in a mentoring context to assist students to meet the course-level objectives faculty have created in their study abroad programs.

Another direction for future research then might follow a deductive line of inquiry in which student learning outcomes specific to the study abroad context/discipline(s) of interest are tied to current assessment tools to determine faculty leader effectiveness in creating the study abroad program and corresponding course(s) to ensure students meet these objectives. It is important to continue to obtain the most objective measures of impact of study abroad, isolating those short and long term changes in student learning and behavior that can be tied directly to participation in these environments, and supporting faculty in developing the most successful and effective programs possible.

Finally, we plan to continue the inductive line of inquiry using the current assessment tools to determine what is happening to students participating in study abroad. A number of additional data analyses are still possible given the information contained in each CHE log entry. For example, experimenters are currently analyzing CHE log entries in each log entry category (e.g., "What I Expected," "What I Saw," "How I Felt," and "Reflection") to get a more specific picture of students' development of perspective taking, cultural awareness, critical thinking, etc. Experimenters have developed a rubric that allows for two independent evaluators to objectively code the narrative feature of the CHE log entries, particularly the "What I Saw" category. Individual student responses are scored as observations of oneself, observations of others, and observations of cultural practices. It is our hope that categorizing student responses on the $\mathrm{CHE} \log$ in this way can give us insight and quantitative data regarding notions of perspective taking and cultural sensitivity in the sense that students are more likely to report observations of interest to him/her. The frequency of reporting in this category then can be interpreted as an indicator of the strength (e.g., Skinner, 1957) of a response and as such then, the importance of such observations of the participant. Further efforts include the development of a rubric that will allow two independent observers to score the "Reflection" category according to developmental markers that would be indicative of students' development of critical thinking skills as a function of participating in the short-term study abroad 
experience. Future analyses should provide suggestions regarding the impact of study-abroad and/or other curricular and co-curricular activities on the development of student outcomes.

Even though the current study may leave us with more questions than answers, it sets the occasion for several new lines of inquiry. First, the current study shows that the CHE log, when used in the context of a short-term study abroad program embedded in a course, can provide orderly information about students' observations across three categories (Cultural, Historical, \& Environmental). Second, the data suggest that point contingencies did drive CHE log completion for more students than in past research (Cihon et al., 2012); however, the point contingencies did not drive responding for all consenting students. Finally, the approach to measuring student development before, during, and after a short-term study abroad experience used in the current investigation can provide additional information regarding the specific changes in student observations that might occur as a function of studying abroad as well as allow for the possibility of more long-term measures of the effects of study abroad experiences. Moreover, this approach to assessing student development may provide a useful set of data for faculty study abroad program leaders to individualize instruction for their participating students to increase the impact of the study abroad experience.

\section{References}

Allen, H. W. (2010). What shapes short-term study abroad experiences? A comparative case study of students' motives and goals. Journal of Studies in International Education, 14, 452-470. doi: $10.1177 / 1028315309334739$

Baer, D. M., Wolf, M. M., \& Risley, T. R. (1968). Some current dimensions of applied behavior analysis. Journal of Applied Behavior Analysis, 1, 91-97.

Bolen, M. C. (Ed). (2007). A Guide to outcomes assessment in education abroad. Carlisle, PA: The Forum on Education Abroad.

Braskamp, L. A., Braskamp, D. C., \& Engberg, M. E. (2014). Global Perspective Inventory (GPI): Its purpose, construction, potential uses, and psychometric characteristics. Global Perspective Institute Inc. Chicago, IL 60611. Retrieved from https://s3.amazonaws.com/academia.edu.documents/44637248/manual.pdf?AWSAccessKeyId=AKI AIWOWYYGZ2Y53UL3A\&Expires=1508170987\&Signature=5HCLDpevQAEnyrTAf4HuWp4hw Ok\%3D\&response-contentdisposition=inline\%3B\%20filename\%3DGlobal_Perspectives_Inventory_GPI_Its_Pu.pdf

Braskamp, L. A., Braskamp, D. C., \& Merrill, K. C. (2009). Assessing progress in global learning and development of students with education abroad experiences. Frontiers: The Interdisciplinary Journal of Study Abroad, 18, 101-118.

Chieffo, L., \& Griffiths, L. (2004). Large scale assessment of student attitudes after a short-term study abroad program. Frontiers: The Interdisciplinary Journal of Study Abroad, 10, 165-167.

Cihon, T. M., \& Stephens, C. J. (2011). Integrating teaching and interdisciplinary scholarship to enhance student learning outcomes. Journal of the Speech and Theatre Association of Missouri, 41, 65-82.

Cihon, T. M., Stephens, C. J., \& Dean B. L. (2012). Global understanding through theatre: Enhancing second language acquisition and cultural competence with interdisciplinary research bridging theatre arts and behavior analysis. Journal of the Speech and Theatre Association of Missouri, 41, 65-82.

Deardorf, D. K. (2006). Identification and assessment of intercultural competence as a student outcome of internationalization. Journal of Studies in International Education, 10(3), 241-266. doi: $10.1177 / 1028315306287002$ 
Goldiamond, I. (1974/2002). Toward a constructional approach to social problems: Ethical and constitutional issues raised by applied behavior analysis. Behavior and Social Issues, 11, 108-197. doi: http://dx.doi.org/10.5210/bsi.v11i2.92

Hegler, K. L. (2004). Assessing learning communities. Assessment Update: Progress, Trends, and Practices in Higher Education, 16, 1-8.

Ingraham, E. C., \& Peterson, D. L. (2004). Assessing the impact of study abroad on student learning at Michigan State University. Frontiers: The Interdisciplinary Journal of Study Abroad, 10, 83-100.

Kehl, K., \& Morris, J. (2007/2008). Differences in global-mindedness between short-term and semesterlong study abroad participants at selected universities. Frontiers: The Interdisciplinary Journal of Study Abroad, 15, 67-69.

Kuh, G. D. (2008). High-impact educational practices: What they are, who has access to them, and why they matter. Washington, DC: Association of American Colleges and Universities.

Kuh, G., \& Ikenberry, S. (2009). More than you think, less than we need: Learning outcomes assessment in American higher education. Urbana, IL: University of Illinois and Indiana University, National Institute for Learning Outcomes Assessment (NILOA).

Lardner, E., \& Malnarich, G. (2008/2009). Assessing integrative learning: insights from Washington Center's national project on assessing learning in learning communities. Journal of Learning Communities Research, 3(3), 1-20.

Michael, J. (1991). A behavioral perspective on college teaching. The Behavior Analyst, 14, 229-239.

Skinner, B. F. (1957). Verbal behavior. New York: Appleton-Century-Crofts.

Steinberg, M. (2002). Involve me and I will understand: Academic quality in experiential programs abroad. Frontiers: The Interdisciplinary Journal of Study Abroad, 8, 253-273.

Stephens, C. J., \& Florini, J. (2010). Globalizing the communication studies and theatre curriculum. Journal of the Speech and Theatre Association of Missouri, 40, 111-127.

Sutton, R. C., Miller, A. N., \& Rubin, D. L. (2007). Research design in assessing learning outcomes of education abroad programs. In M. C. Bolen (Ed.), A Guide to outcomes assessment in education abroad (23-59). Carlisle, PA: The Forum on Education Abroad.

Sutton, R., \& Rubin, D. (2004). The GLOSSARI project: Initial findings from a system-wide research initiative on study abroad learning outcomes. Frontiers: The Interdisciplinary Journal of Study Abroad, 10, 65-82

Tajes, M., \& Ortiz, J. (2010). Assessing study abroad programs: Application of the "SLEPT" framework through learning communities. The Journal of General Education, 59, 17-41. doi: 10.1111/j.21501092.2011.00025_29.x

Williams, T. R. (2009). The reflective model of intercultural competency: A multidimensional, qualitative approach to study abroad assessment. Frontiers: The Interdisciplinary Journal of Study Abroad, 18, 289-206. 